\title{
Environmental enrichment has no effect on the development of dopaminergic and GABAergic fibers during methylphenidate treatment of early traumatized gerbils
}

\author{
Susanne Brummelte 1,3 , Thorsten Grund ${ }^{1}$, Gunther H Moll2 , \\ Gertraud Teuchert-Noodt ${ }^{1}$ and Ralph R Dawirs*2
}

Address: ${ }^{1}$ Department of Neuroanatomy/Cognitive Neuroscience, Faculty of Biology, University of Bielefeld, Universitätsstrasse 25, D-33615 Bielefeld, Germany, ${ }^{2}$ Department of Child and Adolescent Psychiatry, University Hospital Erlangen, Schwabachanlage 6 + 10, D-91054 Erlangen, Germany and ${ }^{3}$ Department of Psychology, University of British Columbia, 2136 West Mall, Vancouver, BC, V6T 1Z4, Canada

Email: Susanne Brummelte - sbrummelte@uni-bielefeld.de; Thorsten Grund - thor.grund@gmx.de; Gunther H Moll - gunther.moll@ukerlangen.de; Gertraud Teuchert-Noodt - g.teuchert@uni-bielefeld.de; Ralph R Dawirs* - ralph.dawirs@uk-erlangen.de

* Corresponding author

Published: 16 May 2008

Journal of Negative Results in BioMedicine 2008, 7:2 doi:10.1 186/1477-5751-7-2

This article is available from: http://www.jnrbm.com/content/7/1/2

(c) 2008 Brummelte et al; licensee BioMed Central Ltd.

This is an Open Access article distributed under the terms of the Creative Commons Attribution License (http://creativecommons.org/licenses/by/2.0), which permits unrestricted use, distribution, and reproduction in any medium, provided the original work is properly cited.
Received: 4 October 2007

Accepted: 16 May 2008

\begin{abstract}
It is widely believed, that environmental factors play a crucial role in the etiology and outcome of psychiatric diseases such as Attention-Deficit/Hyperactivity Disorder (ADHD). A former study from our laboratory has shown that both methylphenidate (MP) and handling have a positive effect on the dopaminergic fiber density in the prefrontal cortex (PFC) of early traumatized gerbils (Meriones unguiculatus). The current study was performed to investigate if enriched environment during MP application has an additional influence on the dopaminergic and GABAergic fiber densities in the PFC and amygdala in this animal model.

Animals received a single early dose of methamphetamine (MA; $50 \mathrm{mg} / \mathrm{kg}$; i.p.) on postnatal day (PD) 14, which is known to cause multiple changes in the subsequent development of several neurotransmitter systems including the dopaminergic systems, and were then treated with oral daily applications of MP (5 mg/kg) from PD30-60. Animals treated this way were either transferred to an enriched environment after weaning (on PD30) or were kept under impoverished rearing conditions.

There was no effect of an enriched environment on the dopaminergic or GABAergic fiber density neither in the PFC nor in the amygdala. With regard to former studies these results underline the particular impact of MP in the treatment of ADHD.
\end{abstract}

\section{Findings}

Methylphenidate (MP) (e.g. Ritalin ${ }^{\circledast}$ ) is a stimulant drug and is the common medicament to treat Attention-Deficit/Hyperactivity Disorder (ADHD) as it is reducing the core symptoms of this frequent adolescent disease $[1,2]$. Being an indirect dopamine (DA) agonist MP blocks the reuptake of DA through the DA transporter and the noradrenalin transporter [3-5], and thus leads to an increased extracellular concentration of DA $[6,7]$. The neurobiological basis of ADHD is basically thought to be characterized by deficient dopaminergic systems $[8,9]$, 
with meso-limbo-cortical and nigro-striatal dopaminergic structures being differentially affected [10-12].

Our lab has studied the long-term plastic effects of methylphenidate (MP) in an animal model of early traumatization, that bears some resemblance to ADHD $[13,14]$. We challenged gerbils (Meriones unguiculatus) with a single non-invasive dose of methamphetamine (MA, $50 \mathrm{mg} / \mathrm{kg}$, i.p.) on postnatal day 14 [15], which causes an imbalance in the dopaminergic system, in particular a reduced DA fiber density in the prefrontal cortex and the nucleus accumbens and an increased dopaminergic innervation in caudal limbic areas [16-18]. The oral application of MP for 30 days to those previously traumatized gerbils, leads to an increase in prefrontal dopaminergic fiber densities compared to controls, which received $\mathrm{H}_{2} \mathrm{O}$ instead [14], thus restoring pristine fiber densities in non-traumatized gerbils (see Fig. 1). However, the fiber densities in the nucleus accumbens and in the amygdala were not or only slightly affected, underlining a rather specific effect of MP $[13,14]$.

Parental care and family environment have been linked to ADHD [19], as e.g. revealed by an association between low social status, early deprivation or high family conflict and ADHD [19-22]. Recent results from an animal study further suggest an association between maternal stress during the postpartum period and hyperactive and impulsive behavior, particularly in the male offspring [23]. However, a good environment has been shown to positively affect the development of young children from adverse family situations [20], underlining the importance of taking social and family milieu into account concerning the diagnosis and treatment of hyperactive children.

The current study was performed to investigate the potentially augmenting effect of an enriched environment on the impact of MP, measured by dopaminergic and GABA fiber densities. The GABAergic and dopaminergic systems are known to exhibit a high interconnectivity with e.g. DA innervating GABAergic cell bodies, dendrites and axon terminals in either a excitatory or inhibitory way [24-26]. As it has further been shown that the GABAergic system reacts with particular changes in its local innervation pattern to an early disturbance of the dopaminergic system $[27,28]$, it is conceivable that GABAergic elements play an essential role in reactive neuroplasticity [29]. Therefore, this transmitter system was additionally investigated to reveal potential adaptation or compensations within the local networks of altered dopaminergic terminal inputs.

Breeding gerbils (Meriones unguiculatus) were obtained from Harlan Winkelmann (Borchen, Germany) and kept under natural day/night cycles with food and water being provided ad libitum. Animals were bred in standard cages (Makrolon type 4) and received a single non-invasive injection of $(+)$-methamphetamine hydrochloride (MA) (Sigma, M 8750; $50 \mathrm{mg} / \mathrm{kg}$, i.p.), on postnatal day 14, causing an imbalance in the dopaminergic system $[16,17]$. On postnatal day (PD) 30, animals were weaned and randomly assigned to one of the two following groups: group $1(\mathrm{n}=9)$ was kept individually in standard cages (Makrolon type 3 ) under impoverished rearing conditions (IR), while group $2(n=11)$ were transferred with their siblings to large compounds $(1 \mathrm{~m} \times 1 \mathrm{~m})$ with an environment consisting of opportunities to hide and play and thus kept under semi-natural enriched rearing conditions (ER). All gerbils received an oral daily application of MP (5 mg/kg; Ritalin ${ }^{\circledast}$ IR, Novartis Pharma GmbH, Nürnberg) from PD30-PD60, which appears to properly simulate clinically relevant treatment [cf. [14]]. MP was administered directly through a pipette, rather than given through the drinking water as gerbils do not use to drink regularly. All experimental procedures were approved by the appropriate committee for animal care in accordance with the European Communities Council Directive and all efforts were made to minimize animal number and suffering.

At PD90 all animals were transcardially perfused under deep chloral hydrate anesthesia ( $1.7 \mathrm{~g} / \mathrm{kg}$, i.p.) with $0.1 \mathrm{M}$ sodium cacodylate $\mathrm{pH}$ 6.2, followed by $5 \%$ glutaraldehyde in $0.1 \mathrm{M}$ sodium cacodylate $\mathrm{pH}$ 7.5. Immediately after perfusion the brains were dissected and $50 \mu \mathrm{m}$ thick frontal sections of the right hemisphere were cut with a vibratome (Leica VT 1000S). The methods used for DA and GABA immunohistochemistry have been published recently $[27,30]$. DA fibers were quantified in different laminae (I, III) of the prefrontal cortex (PFC), in the basolateral amygdala (BLA) and the medial and lateral part of the central amygdala (CA), while GABA fibers were only investigated in the areas were MP has been shown to affect DA fibers before, namely in the PFC (lamina I, II, III and $\mathrm{V} / \mathrm{VI}$ ) and the BLA (anterior, posterior). In the defined region of each section all detectable fiber fragments were visualized using a bright field microscope (BX61, Olympus, Hamburg, Germany) and a digital camera for microscopy (ColorView II, SIS, Münster, Germany). Fibers were quantified by software for image analysis (KS300, Jenoptik, Jena, Germany) and the fiber density was computed as a percentage of the evaluated test area. Fiber densities were analyzed separately for each region with a repeated-measures analysis of variance (ANOVA) with area (subregions; layers) as within-subject factor and rearing condition (impoverished/enriched) as between-subject factors. All calculations were performed using Statistica 6 (StaSoft, Tulsa USA) with significance level set at $\mathrm{p}<0.05\left({ }^{*}\right)$. 

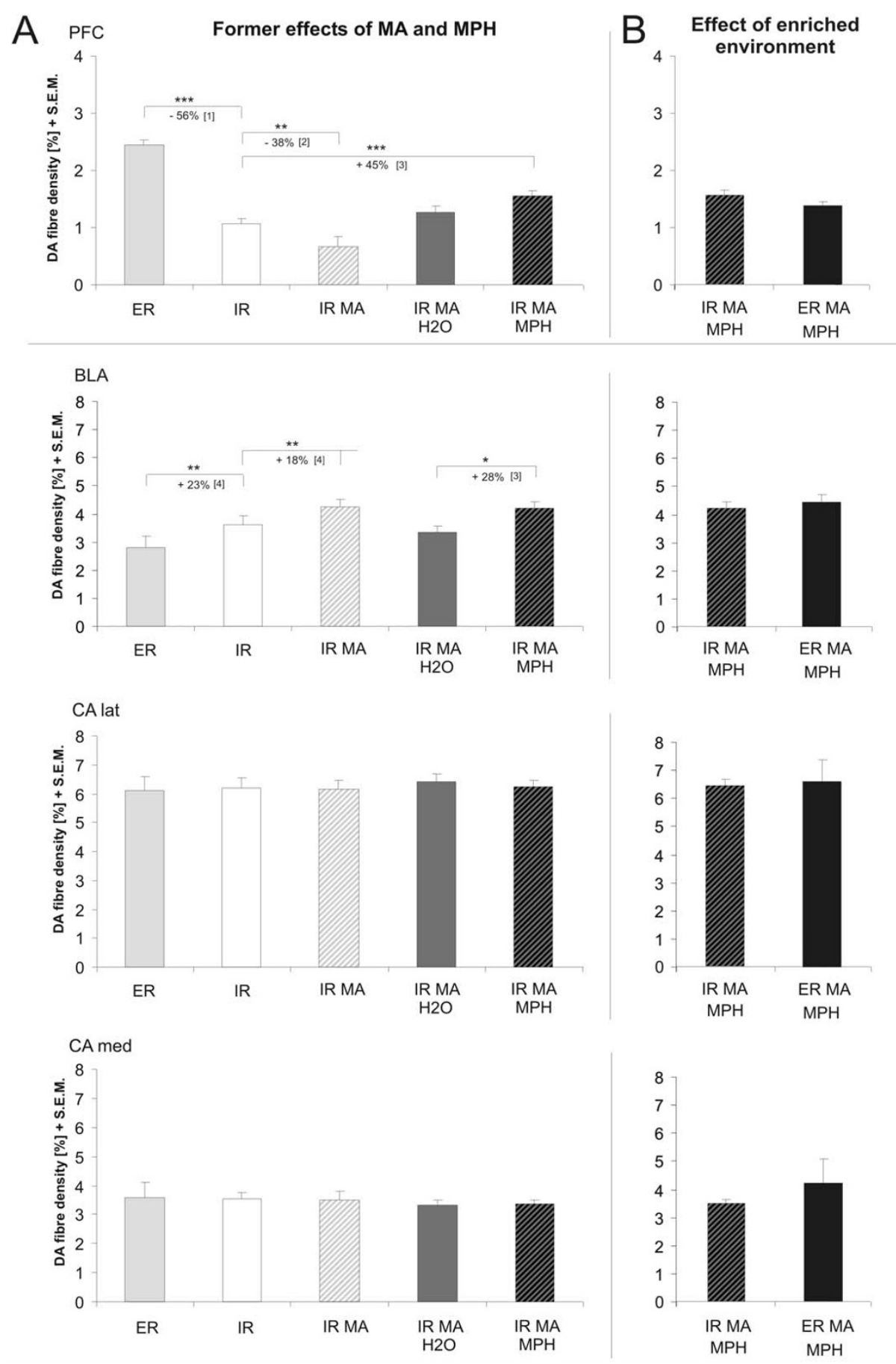

Figure I

A. Overview over previously published effects of methamphetamine (MA) and methylphenidate (MP) on the dopaminergic fiber densities in the amygdala and the medial prefrontal cortex (PFC) of animals from enriched (ER) an impoverished rearing (IR) conditions. Values were nominated to account for possible variations in the data due to different experimenters and procedures to make them comparable. B. Effect of transfer to enriched environment on the dopaminergic fiber density. There was no significant effect in any of the investigated areas. (Therefore data from different laminae of the PFC was combined here). Abbr.: DA: Dopamine; ER. Enriched environment; IR: Impoverished environment; MA: Methamphetamine, MP: Methylphenidate; BLA: Basolateral Amygdala; CA lat. Lateral part of the central amygdala; CA med: Medial part of the central amygdala; PFC: Prefrontal cortex; [I]: Winterfeld et al., 1998; [2]: Dawirs et al., 1994; [3]: Grund et al., 2006; [4]: Busche et al. 2004. 
The repeated measures ANOVA revealed no significant effect of rearing conditions $(\mathrm{F}(1,17)=0.50, \mathrm{p}=0.49)$ or interaction effect of condition and lamina $(\mathrm{F}(1,17)=$ $0.07, \mathrm{p}=0.79$ ) for the DA fibers in the prefrontal cortex, or for the DA fibers in the amygdaloid complex (effect of rearing conditions: $\mathrm{F}(1,16)=1.32, \mathrm{p}=0.27$; interaction effect of condition and area: $F(2,32)=0.8, p=0.46)$. The GABA fibers also revealed no significant effect for the environmental condition (PFC: $F(1,14)=0.89, \mathrm{p}=0.36$; BLA: $\mathrm{F}(1,14)=0.55, \mathrm{p}=0.47)$, nor was there any interaction effect of condition and lamina/area (PFC: F $(3,42)=.30$, $\mathrm{p}=0.82 ; \mathrm{BLA}: \mathrm{F}(1,14)=3.73, \mathrm{p}=0.073)$.

So apparently enriched environment has no augmenting effect on the action of MP on the fiber system of DA (Fig. 1 ), nor were there any adaptive changes in the GABAergic system in the prefrontal cortex or amygdala of afore traumatized gerbils.

There are to date only few studies, which have investigated the long term effects of MP on the developing brain. Moll and colleagues [31] could show that the dopamine transporter density was reduced in rat striatum after early exposure to a clinical dose of MP. In addition, our lab could recently reveal an increase in dopaminergic fiber density in the medial PFC and the BLA of MP treated gerbils which were traumatized by the psychostimulant drug MA [[13]; cf. Fig. 1]. This MA-traumatization, which was also used in the current study, is particularly effective to cause disturbances in the developing rather than in the adult brain [32]. Therefore, the early pharmacological challenge in our animal model is used to create a specific pathological state in the dopaminergic system $[16,17]$ that is likely to mimic behavioral and neuroanatomical aspects of ADHD [13].

Further long-term effects should also be expected from environmental variables, as these are usually thought to play a potentially important role in the modulation of ADHD [20,33-35]. In fact, enriched rearing of animals has been shown to attenuate behavioral changes after brain injuries [36] and improve cognitive functions [37-39]. Therefore, treating ADHD children usually includes a combination of drug treatment and behavioral interventions $[34,40,41]$, although controlled clinical trials gave rise to controversial discussions about the augmenting impact of behavior therapy [34].

Considering the latter it is less surprising that we could not detect any structural improvement in animals, which were transferred from impoverished rearing conditions to an enriched environment while receiving MP. On the other hand, a former study has already revealed an effect of handling on the dopaminergic system without any medication [13]. Interestingly, this handling effect was only significant in saline treated animals and not in MAtreated animals compared to unhandled controls. As animals from impoverished rearing conditions already reveal an altered innervation density of different transmitter systems compared to animals born and reared in semi-natural environment $[[17,39,42-44]$; cf. Fig. 1], this handling effect may be interpreted as a beneficial "therapeutic" intervention [13]. This hypothesis is supported by a study showing, that the increase in extracellular dopamine in the mPFC after MP exposure is significantly elevated when combined with handling [45]. Thus, it is conceivable, that the transfer to an enriched environment has no additional positive consequences. Although most studies so far have concentrated on neonatal handling (for review see [46]) rather than on handling after weaning, the procedure clearly excite functional neuronal adaptations within cortical and endocrine systems $[47,48]$. It would be interesting to investigate the effect of MP during environmental enrichment without the additional handling, however, due to the group housing and irregular drinking habits of gerbils administration of MP through the drinking water is not a suitable alternative.

The late transfer to the enriched environment in our study might be an additional reason for the failure of this intervention to reveal any differences. Therefore, a functional improvement in the transmitter systems might be possible by environmental enrichment but structural changes might be sensitive to critical phases or the beneficial impact might be obscured by the dominating effects of $\mathrm{MP}$ or the impact of handling.

\section{List of Abbreviations}

ADHD: Attention-Deficit/Hyperactivity Disorder; MP: methylphenidate; PFC: prefrontal cortex; MA: methamphetamine; DA: dopamine; BLA: basolateral amygdala; CA: central amygdala

\section{Competing interests}

The authors declare that they have no competing interests.

\section{Authors' contributions}

SB participated in the acquisition and interpretation of the data and drafted the manuscript.

TG contributed to the acquisition and the analysis of the data

GM contributed to the study conception design and interpretation of data.

GT participated in the design of the study, and the drafting and revision of the manuscript. 
$\mathrm{RD}$ participated in the design of the study and the critical reviewing of the manuscript.

All the authors have read and approved the final manuscript.

\section{Acknowledgements}

The authors would like to thank Jan-Oliver Sprenger, Sandra Rütherhenke and Dr. Francesco Bagorda for excellent technical assistance.

\section{References}

I. Rothenberger A, Danckaerts M, Dopfner M, Sergeant J, Steinhausen HC: EINAQ -- a European educational initiative on Attention-Deficit Hyperactivity Disorder and associated problems. Eur Child Adolesc Psychiatry 2004, I3 Suppl I:13 I-I35.

2. Fone KC, Nutt DJ: Stimulants: use and abuse in the treatment of attention deficit hyperactivity disorder. Curr Opin Pharmacol 2005, 5:87-93.

3. Froimowitz M, Patrick KS, Cody V: Conformational analysis of methylphenidate and its structural relationship to other dopamine reuptake blockers such as CFT. Pharm Res 1995, 1 2:1430-1434.

4. Gatley SJ, Pan D, Chen R, Chaturvedi G, Ding YS: Affinities of methylphenidate derivatives for dopamine, norepinephrine and serotonin transporters. Life Sci 1996, 58:231-239.

5. Carboni E, Silvagni A: Dopamine reuptake by norepinephrine neurons: exception or rule? Crit Rev Neurobiol 2004, 16:12I-128.

6. Volkow ND, Wang G, Fowler JS, Logan J, Gerasimov M, Maynard L, Ding Y, Gatley SJ, Gifford A, Franceschi D: Therapeutic doses of oral methylphenidate significantly increase extracellular dopamine in the human brain. I Neurosci 200I, 2I:RCI2I.

7. Bymaster FP, Katner JS, Nelson DL, Hemrick-Luecke SK, Threlkeld PG, Heiligenstein JH, Morin SM, Gehlert DR, Perry KW: Atomoxetine increases extracellular levels of norepinephrine and dopamine in prefrontal cortex of rat: a potential mechanism for efficacy in attention deficit/hyperactivity disorder. Neuropsychopharmacology 2002, 27:699-7II.

8. Sagvolden T, Johansen EB, Aase H, Russell VA: A dynamic developmental theory of attention-deficit/hyperactivity disorder (ADHD) predominantly hyperactive/impulsive and combined subtypes. Behav Brain Sci 2005, 28:397-419.

9. Russell VA, Sagvolden T, Johansen EB: Animal models of attention-deficit hyperactivity disorder. Behav Brain Funct 2005, I:9.

10. Ernst M, Zametkin AJ, Matochik JA, Pascualvaca D, Jons PH, Cohen RM: High midbrain [I8F]DOPA accumulation in children with attention deficit hyperactivity disorder. Am J Psychiatry 1999, 156:1209-1215.

II. Castellanos FX: Toward a pathophysiology of attention-deficit/ hyperactivity disorder. Clin Pediatr (Phila) 1997, 36:38I-393.

12. Johansen EB, Aase H, Meyer A, Sagvolden T: Attention-deficit/ hyperactivity disorder (ADHD) behaviour explained by dysfunctioning reinforcement and extinction processes. Behav Brain Res 2002, 130:37-45.

13. Grund T, Lehmann K, Bock N, Rothenberger A, Teuchert-Noodt G: Influence of methylphenidate on brain development - an update of recent animal experiments. Behav Brain Funct 2006, 2:2.

14. Grund T, Teuchert-Noodt G, Busche A, Neddens J, Brummelte S, Moll GH, Dawirs RR: Administration of oral methylphenidate during adolescence prevents suppressive development of dopamine projections into prefrontal cortex and amygdala after an early pharmacological challenge in gerbils. Brain Res 2007, I I 76C: I24-132.

15. Teuchert-Noodt G, Dawirs RR: Age-related toxicity in prefrontal cortex and caudate-putamen complex of gerbils (Meriones unguiculatus) after a single dose of methamphetamine. Neuropharmacology 1991, 30:733-743.

16. Dawirs RR, Teuchert-Noodt G, Czaniera R: The postnatal maturation of dopamine innervation in the prefrontal cortex of gerbils (Meriones unguiculatus) is sensitive to an early single dose of methamphetamine. A quantitative immunocytochemical study. J Hirnforsch 1994, 35:195-204.
17. Busche A, Polascheck D, Lesting J, Neddens J, Teuchert-Noodt G: Developmentally induced imbalance of dopaminergic fibre densities in limbic brain regions of gerbils (Meriones unguiculatus). J Neural Transm 2004, I I I:45 I-463.

18. Lesting J, Neddens J, Busche A, Teuchert-Noodt G: Hemispherespecific effects on serotonin but not dopamine innervation in the nucleus accumbens of gerbils caused by isolated rearing and a single early methamphetamine challenge. Brain Res 2005, 1035: 168-176.

19. Pressman LJ, Loo SK, Carpenter EM, Asarnow JR, Lynn D, McCracken JT, McGough JJ, Lubke GH, Yang MH, Smalley SL: Relationship of family environment and parental psychiatric diagnosis to impairment in ADHD. J Am Acad Child Adolesc Psychiatry 2006, 45:346-354.

20. Ornoy A: The impact of intrauterine exposure versus postnatal environment in neurodevelopmental toxicity: long-term neurobehavioral studies in children at risk for developmental disorders. Toxicol Lett 2003, |40-|4|:|7|-|8|.

21. Biederman J, Milberger S, Faraone SV, Kiely K, Guite J, Mick E, Ablon $S$, Warburton R, Reed E: Family-environment risk factors for attention-deficit hyperactivity disorder. A test of Rutter's indicators of adversity. Arch Gen Psychiatry 1995, 52:464-470.

22. Kreppner JM, O'Connor TG, Rutter M: Can inattention/overactivity be an institutional deprivation syndrome? J Abnorm Child Psychol 2001, 29:513-528.

23. Brummelte S, Pawluski JL, Galea LA: High post-partum levels of corticosterone given to dams influence postnatal hippocampal cell proliferation and behavior of offspring: A model of post-partum stress and possible depression. Horm Behav 2006, 50:370-382.

24. Sesack SR, Snyder CL, Lewis DA: Axon terminals immunolabeled for dopamine or tyrosine hydroxylase synapse on GABA-immunoreactive dendrites in rat and monkey cortex. J Comp Neurol 1995, 363:264-280.

25. Geldwert D, Norris JM, Feldman IG, Schulman JJ, Joyce MP, Rayport $S$ : Dopamine presynaptically and heterogeneously modulates nucleus accumbens medium-spiny neuron GABA synapses in vitro. $B M C$ Neurosci 2006, 7:53.

26. Liu F, Wan Q, Pristupa ZB, Yu XM, Wang YT, Niznik HB: Direct protein-protein coupling enables cross-talk between dopamine $D 5$ and gamma-aminobutyric acid $A$ receptors. Nature 2000, 403:274-280.

27. Brummelte S, Neddens J, Teuchert-Noodt G: Alteration in the GABAergic network of the prefrontal cortex in a potential animal model of psychosis. J Neural Transm 2007, I | 4:539-547.

28. Dawirs RR, Teuchert-Noodt G, Nossoll M: Pharmacologically induced neural plasticity in the prefrontal cortex of adult gerbils (Meriones unguiculatus). Eur J Pharmacol 1997, 327: $117-123$.

29. Teuchert-Noodt G: Neuronal degeneration and reorganization: a mutual principle in pathological and in healthy interactions of limbic and prefrontal circuits. J Neural Transm Suppl 2000:315-333

30. Lesting J, Neddens J, Teuchert-Noodt G: Ontogeny of the dopamine innervation in the nucleus accumbens of gerbils. Brain Res 2005, 1066: 16-23.

3I. Moll GH, Hause S, Ruther E, Rothenberger A, Huether G: Early methylphenidate administration to young rats causes a persistent reduction in the density of striatal dopamine transporters. J Child Adolesc Psychopharmacol 200I, I I:I5-24.

32. Brummelte S, Grund T, Czok A, Teuchert-Noodt G, Neddens I: Long-term effects of a single adult methamphetamine challenge: minor impact on dopamine fibre density in limbic brain areas of gerbils. Behav Brain Funct 2006, 2:12.

33. Biederman J, Faraone SV, Monuteaux MC: Differential effect of environmental adversity by gender: Rutter's index of adversity in a group of boys and girls with and without ADHD. Am J Psychiatry 2002, 159:1556-1562.

34. Rothenberger A, Dopfner M, Sergeant J, Steinhausen HC: ADHD beyond core symptoms. Not only a European perspective. Eur Child Adolesc Psychiatry 2004, I 3:Suppl I [http://springerlink.met apress.com/content/666198j749ap/

? $\mathrm{p}=26033 \mathrm{~b} 42 \mathrm{cc} 60483 \mathrm{~d} 8 \mathrm{a} 54 \mathrm{dbfb} 392364 \mathrm{da} \& \mathrm{pi}=37]$.

35. Hurtig T, Taanila A, Ebeling H, Miettunen J, Moilanen I: Attention and behavioural problems of Finnish adolescents may be 
related to the family environment. Eur Child Adolesc Psychiatry 2005, I 4:47I-478.

36. Kolb B, Gibb R: Environmental enrichment and cortical injury: behavioral and anatomical consequences of frontal cortex lesions. Cereb Cortex 1991, I:189-198.

37. Kobayashi S, Ohashi $Y$, Ando S: Effects of enriched environments with different durations and starting times on learning capacity during aging in rats assessed by a refined procedure of the Hebb-Williams maze task. I Neurosci Res 2002, 70:340-346.

38. Rema $V$, Ebner FF: Effect of enriched environment rearing on impairments in cortical excitability and plasticity after prenatal alcohol exposure. J Neurosci 1999, 19:10993-I 1006.

39. Winterfeld KT, Teuchert-Noodt G, Dawirs RR: Social environment alters both ontogeny of dopamine innervation of the medial prefrontal cortex and maturation of working memory in gerbils (Meriones unguiculatus). J Neurosci Res 1998, 52:20I-209.

40. Taylor E, Dopfner M, Sergeant J, Asherson P, Banaschewski T, Buitelaar J, Coghill D, Danckaerts M, Rothenberger A, Sonuga-Barke E, Steinhausen HC, Zuddas A: European clinical guidelines for hyperkinetic disorder -- first upgrade. Eur Child Adolesc Psychiatry 2004, I 3 Suppl I:17-30.

4I. Banaschewski T, Coghill D, Santosh P, Zuddas A, Asherson P, Buitelaar J, Danckaerts M, Dopfner M, Faraone SV, Rothenberger A, Sergeant J, Steinhausen HC, Sonuga-Barke EJ, Taylor E: Long-acting medications for the hyperkinetic disorders. A systematic review and European treatment guideline. Eur Child Adolesc Psychiatry 2006, 15:476-495.

42. Bagorda F, Teuchert-Noodt G, Lehmann K: Isolation rearing or methamphetamine traumatisation induce a "dysconnection" of prefrontal efferents in gerbils: implications for schizophrenia. J Neural Transm 2006, I I 3:365-379.

43. Neddens J, Bagorda F, Busche A, Horstmann S, Moll GH, Dawirs RR, Teuchert-Noodt G: Epigenetic factors differentially influence postnatal maturation of serotonin (5-HT) innervation in cerebral cortex of gerbils: interaction of rearing conditions and early methamphetamine challenge. Brain Res Dev Brain Res 2003, 146: I19-130.

44. Neddens J, Brandenburg K, Teuchert-Noodt G, Dawirs RR: Differential environment alters ontogeny of dopamine innervation of the orbital prefrontal cortex in gerbils. J Neurosci Res 200I, 63:209-2।3

45. Marsteller DA, Gerasimov MR, Schiffer WK, Geiger JM, Barnett CR, Borg JS, Scott S, Ceccarelli J, Volkow ND, Molina PE, Alexoff DL, Dewey SL: Acute handling stress modulates methylphenidate-induced catecholamine overflow in the medial prefrontal cortex. Neuropsychopharmacology 2002, 27:163-170.

46. Meaney MJ, Mitchell JB, Aitken DH, Bhatnagar S, Bodnoff SR, Iny LJ, Sarrieau A: The effects of neonatal handling on the development of the adrenocortical response to stress: implications for neuropathology and cognitive deficits in later life. Psychoneuroendocrinology 1991, 16:85-103.

47. Sieck G, Ramaley JA: Effects of early handling upon puberty: correlations with adrenal stress responsiveness. Physiol Behav I 975, I 5:487-489.

48. Severino GS, Fossati IA, Padoin MJ, Gomes CM, Trevizan L, Sanvitto $G L$, Franci CR, nselmo-Franci JA, Lucion AB: Effects of neonatal handling on the behavior and prolactin stress response in male and female rats at various ages and estrous cycle phases of females. Physiol Behav 2004, 81 : 489-498.

\section{Publish with Bio Med Central and every scientist can read your work free of charge}

"BioMed Central will be the most significant development for disseminating the results of biomedical research in our lifetime. "

Sir Paul Nurse, Cancer Research UK

Your research papers will be:

- available free of charge to the entire biomedical community

- peer reviewed and published immediately upon acceptance

- cited in PubMed and archived on PubMed Central

- yours - you keep the copyright

Submit your manuscript here:

http://www.biomedcentral.com/info/publishing_adv.asp
BioMedcentral 